earth; but if he fail in discharging the duties assigned to him, these same elements rise up against him, and by inducing fatal disease, remove him as an useless cumberer of the ground.

The relation of man to the earth, and of the earth to man, is mutual, or, as Koreff, in his work $D e$ Regionibus Italia aere, pernicioso contaminatis Observationes, expresses it, "Not only does man need the earth in order to live and be active, but the earth also stands in need of man."

That trees which can be proved to diminish, to lessen, instead of increase, the amount of oxygen, are no fit portion of the vegetation of cemeteries, must be obvious; yet these are those most likely to find a place there, being held to be, almost by prescriptive right, the appropriate occupants of the spots set apart for the dead-" dark trees, funereal, cypress, yew and shadowy pine, and spicy cedar." Which give to our burial-grounds an aspect scarcely less gloomy and repulsive than those in the neighbourhood of Constantinople, so graphically described in "Anastatius."

Evergreens generally are allowable, but all those which contain volatile oils, or volatile constituents in general, which change into resin by the absorption of oxygen (see Liebig's Organic Chemistry applied to Agriculture, first edition, p. 28), are very unfit. If we exclude the coniferous plants above enumerated, we shall still have enough of perennial leaved plants left to maintain an appearance of freshness and life throughout winter, the cherry-laurel (cerasus laurocerasus), the Portugal laurel (cerasus lusitanica), holly, ilex aquifolium, and, above all, the arbutus unedo, and arbutus andrachne, from being clothed during the winter with "blossoms and fruit at once." Where walls surround the cemetery, the mespilus pyracantha, and other shrubs, might be advantageously trained against them. Among deciduous plants it would be necessary to exclude the poplars, especially the populus balsamifera. Along the sides of large cemeteries the ash tree might be planted, as the leaves in this country are rarely eaten by insects, and the roots creeping along the surface would not dip down into the graves as elms would do. The ornus europœa, or flowering ash, would be a suitable tree, more cheerful than the weeping ash.

One of the most appropriate would be the common lilac (syringa vulgaris), the leaves of which have been ascertained by Dr. Daubeny to raise the proportion of oxygen, in a jar filled with common air to 29 or 30 per cent., and by introducing several plants into the same jar in pretty quick succession, even raising the proportion from 21 (the ordinary amount) to 39 per cent., thus almost doubling it. "How great, then," says Dr. Daubeny, "must be the effect of an entire tree in the open air under favorable circumstances!" It is less, however, the object of these remarks to show what plants should, as to indicate what should not, be admitted into our proposed cemeteries.

The cypress, yew, cedar, and arbor vitæ are those I am anxious to exclude. One result of their banishment would be, that a more cheerful aspect would appertain to the spots where the remains of our departed friends repose. They would then invite to frequent visits on the part of the survivors; constituting fit retreats, where "the soul might plume and balance her wings by holy meditation, before she should take her own flight to heaven." All these trees belong to one class, termed non-reproductive, because, when cut down, no shoots spring from the roots. This was one reason why the ancients selected the cypress to plant by the grave, which to them was the end of existence. Viewed in this light, it has been well observed, " the cypress is no meet emblem of the Christian's grave." Let us not, then, lose the present opportunity of casting aside the selected emblems of the heathens, and of those who sit in darkness little less profound, but substitute others, more in accordance with that religion which, having "brought life and immortality to light," forbids us, when we commit "earth to earth, ashes to ashes, dust to dust," to sorrow "even as others which have no hope."

In conclusion, I am not without trust that this sug. gestion will meet with attention, since science and religion alike combine in demanding the change.

\section{ON THE MISCHIEFS}

RESULTING FROM

\section{THE RANDOM ADMINISTRATION OF LARGE} DOSES OF CALOMEL.

By Robert Druitt, Esq., Surgeon, London.

\section{TO THE EDITORS OF. THE PROVINCIAL MEDICAL} JOURNAL.

Gentramen,-I send you the following case for insertion in your valuable Journal, in the hope that it may serve as a caution to your readers against following implicitly a practice which is recommended by very high authorities, but which, as the sequel will show, may occasionally be followed by very serious mischief.

The practice to which I allude is the administration of very large doses of calomel, in order to act as a purgative in puerperal convulsions, or other cases of sudden and dangerous congestive affections. This practice is recommended, however, in puerperal convulsions by a majority of the most popular midwifery authors of the present day.

Dr. Rigby, in his treatise on Midwifery in the Library of Practical Medicine, says, when speaking of the treatment of puerperal convulsions, " eight or ten grains of calomel with fifteen or twenty of jalap, should be mixed into a paste with a little thin gruel, and laid upon the back of the tongue," \&c. \&c.

Dr. F. Ramsbotham, in his "Principles and Practice of Midwifery," says that " ten or twelve grains of calomel may be mixed with a little sugar, and put upon the tongue," \&c.

Dr. Fleetwood Churchill, in his "Theory and Practice of Midwifery," recommends a strong cathartic of calomel and jalap to be administered.

Dr. Merriman says, in his " Synopsis of Difficult Parturition," "If the patient be able to swallow, a pill containing from five to ten grains of calomel may be got down; or the calomel mixed with moist sugar may be put into the mouth," \&c. \&c.

The very learned Dr. Copland, in the "Dictionary of Practical Medicine," Art. Convulsions says, "the exhibition of ten grains of calomel, and from five to ten grains of camphor, with or without an equal 
quantity of musk, and shortly afterwards two or three drops of croton oil, should never be omitted."

Lastly, Dr. Robert Lee, in his lectures recently published, directs the practitioner " to put ten grains or a scruple of calomel upon the tongue, or two drops of croton oil, if the bowels require immediate relief," \&c. \&c.

Now fully agreeing, as I do, and as every one must, in the necessity of employing some most energetic and quickly operating remedy, for the purpose of producing a copious discharge of the various excretions, I would contend that calomel is not the most speedy and certain remedy within our reach, and that the use of it in such large doses as those above recommended is highly objectionable.

In the beginning of last May I was sent for, just before bedtime, to see a young lady whom I was engaged to attend in her first confinement. She was then just at the beginning of the seventh month. She had complained of dull headache and drowsiness for the last few days; her face was puffy, her water very scanty, and bowels confined. She had taken no food during the day, and now began to be troubled with retchings, which brought up a small quantity of bile. She had always been remarkably healthy, and had had nothing to do with illness or medicine from the time that she was a child. I prescribed an active cathartic, of which blue pill formed a small part, and a saline draught as a diuretic, and left her for the night.

About three hours afterwards, however, I was summoned to her in great haste, and found her laboring under violent convulsions. These continued at intervals from ten in the morning until about nine. The patient was bled largely twice, but the fits were not entirely subdued till more blood had been abstracted by cupping from the nape of the neck. I suppose the patient lost altogether rather more than fifty ounces of blood. But in the mean time I did not neglect the excernent functions. I gave eight grains of calomel with some jalap as soon as the patient was able to swallow, and followed this up with enemata, and salines with tartar emetic, till the bowels were well unloaded, and the kidneys acted plentifully; and in the course of the day I had the satisfaction to see my patient apparently free from danger.

The same evening, however, she began to complain that her tongue was swelled and painful, which was not much wondered at, as it had been severely wounded by the teeth during the paroxysms of convulsions. The next day this swelling very greatly increased, and the face began also to swell; in fact, there came on the most frightful state of salivation that ever I witnessed. The face and throat were enormously swelled, and the eyelids perfectly closed by the œdema ; the tongue projected immensely from the mouth, and it was many days before it could be replaced; the membrane covering the under surface of the tongue, and the insides of the cheeks and gums, sloughed, and the saliva dribbled away so profusely that it thoroughly soaked from five to six dozen napkins in the course of the twenty-four hours. In the midst of this misery, five days after the convulsions, the patient was delivered of an infant still born.

It was, as may well be imagined, a month before the patient was strong enough to go out of town for change of air ; but a very much longer time elapsed before the mouth had become firm enough to permit of the mastication of solid food, and after that a new misfortune appeared. The inside of the cheeks and the gums, and the under surface of the tongue, which had sloughed, healed with a dense white cicatrix, which very greatly impeded the motion of the tongue in speech and mastication, and prevented the mouth from being opened more than a quarter of an inch. This she has not yet recovered from, and I suppose never will altogether.

The treatment which I employed for the ptyalism consisted of mild aperients and tonics, with sedatives to allay the pain, and as much liquid nourishment as could conveniently be taken. The local applications, for which the patient always expressed herself most grateful, consisted first of washing out the mouth thoroughly with a weak lotion of chloride of lime, and then immediately brushing over the whole interior of it with a lotion containing five grains of tannin to an ounce of distilled water. This immediately coagulated the viscid secretions of the mouth, and enabled the patient to get rid of them without much effort, and thus was a source of great comfort. I employed leeches to the swollen salivary glands, but could not perceive that they did any good. A gargle of six grains of acetate of lead to six ounces of distilled water, with an ounce of simple oxymel, appeared to check the flow of saliva at a subsequent stage.

In order to remedy the contraction of the mouth, she has had her teeth cleaned by a dentist, who removed one which was decayed, and I have employed an instrument to expand the jaws gradually with the aid of a screw; but I believe that time, together with the patient's own efforts, have done more for her than any artificial means. There is an exceedingly gristly band of cicatrix on each side along the anterior border of the masseter muscle. Should it be necessary, these, with some of the fibres underneath, might be divided at a future period. But up to the present time the state of the mouth has been gradually improving, so that the patient can eat with tolerable expedition with her incisor and bicuspid teeth; still there is not yet sufficient space between the molars to render them serviceable.

I think that the occurrence of such a case as the foregoing may well be a caution to others, as it most certainly will be to me, not to administer such a large dose of calomel again under similar circumstances. It must be very obvious that the copious bleeding. which is used at the same time, must tend greatly to increase the rapidity with which the poison is absorbed, and the susceptibility to suffer from it in the worst degree. But even if no objection could be found against the practice on this account, I think it may be shown that calomel is not the remedy best calculated for the emergency. The object is to excite all the excretory functions as rapidly and fully as possible, to reduce the heart's action, and relieve congestion. But calomel is most capricious in its evacuant efforts, and not by any means to be compared with tartar emetic, either in the rapidity or certainty of its action. As for the danger of vomiting, I believe it to be very much overrated, and, if bleed- 
ing is properly performed, would not hesitate to produce it. Certainly one convulsive fit must cause a far greater risk of rupturing a blood-vessel in the brain than any mere efforts of retching.

I am, Gentlemen,

Your obedient servant, Robert Druitt. 6, Bruton-street, Berkeley-square, London, Feb. 26, 1844.

\section{PROVINCIAI, MEDICAL JOURNAL}

SATURDAY, MARCH 2, 1844.

\section{COUNTER PRACTICE OF DRUGGISTS.} SALE OF POISONS FOR CHILDREN.

OBSERVATIONS ON A LATE INQUEST AT STOURBRIDGE.

That men may do what they like with their own, seems at first sight a fair and reasonable doctrine. But yet the safety of the public requires that some limitations should be placed upon it in practice:

We suppose that it would hardly be possible, even if desirable, to make and enforce any legal enactment that would prevent persons from drugging themselves with quack medicines, or that would prevent the chemist from selling them. A man's health is his own, and he insists on his right to do what he likes with it ; and the chemist says the same of his drugs.

But, considering the number of helpless children, who are annually poisoned with " sleeping stuff," Godfrey's cordial, soothing syrup, and other "real blessings to mothers" (vide advertisement), we cannot help thinking that the legislature might interpose in behalf of these victims of maternal ignorance or sloth.

The case is not a mere possibility, or one of rare occurrence; bnt week after week we read of infants destroyed by narcotic medicines, administered by careless hands, and most probably in cases in which they were altogether unnecessary; although, as is very well known, they are remedies which are exceedingly noxious during the period of childhood, except under peculiar circumstances, in which medical skill and circumspection should always superintend their employment.

It is perfectly notorious that they are generally given, not only in order to smother the natural sense of inquietude, produced by improper feeding, bad nursing, a dirty state of the skin, or want of proper exercise and fresh air, but also for the purpose of allowing the nurse or mother an opportunity for going out to take her pleasure. Thus they afford facilities to mothers for neglecting the first and most sacred of their duties.

As for the chemists who sell these deleterious drugs, they are, as is well known, perfectly incompetent to decide on the cases in which they may be used with safety. They regard them as mere articles of traffic ; and in their opinion the more they sell the better. They cannot, however, plead ignorance of the sacrifice of infant life at which their contemptible gains are procured.

Now we cannot see the difficulty of at least lessening the amount of this pernicious practice by a stringent penal enactment. Might not penalties be provided against the selling or administering narcotic drugs to children without the sanction of a legally authorised practitioner? or might not some severe punishment be inflicted both on the seller and the giver, in case of death resulting? A few instances of the kind would soon operate as a wholesome caution.

We have been led to make the foregoing remarks in consequence of a report of a coroner's inquest at Stourbridge, which appeared in the "Ten Towns" Messenger," a Kidderminster paper, of the 23rd of February. The case was that of a child poisoned by some combination of drugs called child's cordial, by which we suppose Godfrey's cordial is meant. We will extract the evidence at full length.

The mother of the child deposed that " it had been poorly a month or six weeks, and very bad for three days. Mrs. Batch said the baby was much worse than I thought it was, and thought it would be proper to show it to a medical man. This was Sunday afternoon, about three o'clock. I did not show it to a medical man, but sent for some child's cordial at five minutes past six in the evening. I have been in the habit of giving the child cordial. I told the boy (my brother) to go to the first shop, which was Johnson's; my father told him to go to the nearest place. When he returned I gave a little of it to the child; the quantity I gave was three parts of a teaspoonful. I have been in the habit of giving the child two spoonfuls at a time. I tried to comfort him, but he did not go to sleep till nine in the evening. He had had no rest. I saw no difference in him up to that time. He never woke again. [Here the witness, who was a respectable-looking woman, was much affected.] He must have died at about a quarter to two the nex.t day. The child was still in bed, and never awoke after Sunday night. It was restless as usual, therefore I was not alarmed.

"By the Coroner-The child slept with my little sister, Elizabeth. I called sometimes to see if the baby was comfortable, and got up about seven o'clock in the morning. The child was asleep, and seemed very comfortable, more than usual. I noticed him several times during the day; he was asleep all the time. I went up stairs at half-past two o'clock, and saw something coming out of his mouth of a dark color. I turned off the clothes, and could not hear him breathe. I fancied he was convulsed a little. I put my head close to his, and found him cold and dead. I gave the alarm, and ran into somebody's house, crying out, ' My child, my child.' Mr. Batch's daughter, Mary Ann, came up stairs, and brought the baby down. I remember nothing more of the matter.

"Re-examined-The child had not been sick before I saw the black on its mouth. Had had no medical advice. I thought it was his teeth. He had 